\title{
Applying DESyne coronary stent system in patients with ischemic heart disease: experience from Jordan
}

This article was published in the following Dove Press journal:

Medical Devices: Evidence and Research

\author{
Mohamad I Jarrah' \\ Nasr Alrabadi ${ }^{2}$ \\ Karem H Alzoubi ${ }^{3}$ \\ 'Department of Internal Medicine, \\ Faculty of Medicine, Jordan University \\ of Science and Technology, Irbid, \\ Jordan; '2Department of Pharmacology, \\ Faculty of Medicine, Jordan University \\ of Science and Technology, Irbid, \\ Jordan; ${ }^{3}$ Department of Clinical \\ Pharmacy, Faculty of Pharmacy, Jordan \\ University of Science and Technology, \\ Irbid, Jordan
}

Background: The safety and efficacy of drug-eluting coronary stenting have been established for various degrees of severity of coronary artery disease. The DESyne is a contemporary cobalt-chromium thin-strut stent which has been studied in low-risk patients so far.

Aim: The aim of this study was to evaluate the safety, efficacy and performance of the DESyne stent in patients with an indication for coronary stent implantation at the King Abdullah University Hospital (KAUH), Jordan.

Patients and methods: Hospital records for all patients implanted with DESyne stent were retrospectively reviewed. Specific clinical events were recorded for all cases, and their incidence rates were estimated by the Kaplan-Meier method. A total of 715 patients $(79.3 \%$ males and $58.3 \%$ with diabetes) with a mean age of $57.8 \pm 10.3$ years were enrolled in this study. An acute coronary syndrome was the most frequent indication for stenting in $86.3 \%$ of the patients (unstable angina $72.0 \%$, myocardial infarction [MI] 14.3\%). A total of 849 lesions (1.2 lesions/ patient) were treated with the DESyne stent.

Results: After 1 year of follow-up, the death rates from cardiac or noncardiac causes were $0.6 \%$ and $1.1 \%$, respectively. MI was observed in $0.9 \%$ of the cases, and an ischemia-driven revascularization was performed in $0.8 \%$ of them. The definite/probable stent thrombosis rate was $1.1 \%$. Conclusion: Favorable clinical event rates including cardiac death, MI and stent thrombosis were observed for the DESyne stent in ischemic heart patients especially those with high prevalence of diabetes mellitus and acute coronary syndrome.

Keywords: coronary stent system, DESyne stent, ischemic heart disease

\section{Introduction}

Percutaneous coronary intervention (PCI) has tremendously improved the treatment of coronary artery disease. Since the first balloon angioplasty for a short proximal lesion in the left anterior descending artery in 1977, millions of patients have benefited from coronary interventions. ${ }^{1,2}$ Over the years, there have been major advancements in the availability of different stent devices that have enabled the widespread use of this therapy. Stent devices are important to overcome the complications with balloon angioplasty, in particular, closure of the vessel during or in the immediate period after the procedure to prevent the vessel from acute recoil and seal eventual dissections. ${ }^{3}$

Stents, as permanent implants, also reduced the incidence of restenosis caused by negative remodeling of the vessel, which is a process that mainly occurred in the first year after the procedure. ${ }^{4}$ Although the initial angioplasty balloon and stents were bulky and relatively stiff, device improvements have resulted in low-profile highly flexible stent-balloon combinations that can easily navigate tortuous anatomies and reach the
Department of Internal Medicine, Facut of Medicine, Jordan University of Science and Technology, Irbid 22 I I0, Jordan

Tel $+96227201000 \times 23521$

Fax +962 27201075

Email mijarrah@just.edu.jo 
majority of the lesions within the coronary vasculature. ${ }^{5}$ The initial problem of stent thrombosis has been managed by high-pressure implantation techniques and the administration of potent antiplatelet medications. ${ }^{6,7}$

Early in this century, drug-eluting stents were introduced. ${ }^{8}$ These stents are coated with polymer materials, and those polymers are loaded with an antiproliferative drug that elutes over a period of few months. ${ }^{9}$ This strategy was highly efficient in reducing the incidence of restenosis which is caused by the previously mentioned neointimal growth or negative remodeling. ${ }^{10}$ These developments have expanded the treatment of single and short lesions initially in patients with stable angina pectoris to the full parade of patients and lesion subsets. ${ }^{11}$ Saying that, coronary stents are continued to be developed further providing improvements on patients' clinical conditions and less rates of complications.

The DESyne ${ }^{\circledR}$ coronary stent system is a next-generation drug-eluting stent based upon a cobalt-chromium platform with a novel design and a drug-/polymer-coating technology that allows for thin struts. To the best of our knowledge, it has the lowest polymer load and lowest drug concentration of any drug-eluting stents currently available in the market. The DESyne coronary drug-eluting stent has been evaluated in a study with relatively selected patients. ${ }^{12}$ The objective of this retrospective study was to report the procedure and the clinical outcomes of patients implanted with the DESyne stent in daily practice, representing a real-world population at the King Abdullah University Hospital (KAUH), Ar Ramtha, Jordan.

\section{Patients and methods}

\section{Patient selection and study design}

A retrospective single-center study was conducted. The hospital records for all patients with one or more DESyne coronary stent implantations were reviewed. There were no specific patient inclusion or exclusion criteria. Data on demographics, cardiac history, cardiovascular risk factors, vessel and lesion characteristics, procedure, antiplatelet medication and specific cardiovascular events that occurred in the followup period of 1 year were obtained. If patients were referred by other centers, either the referring cardiologist or the general practitioner was contacted to obtain follow-up information. An expert operator reviewed all angiograms and assessed the qualitative vessel and lesion characteristics; the quantitative variables were visually assessed. The study was approved by the ethics committee of our university hospital (KAUH). The institutional review board (IRB) approval from KAUH was granted before starting the study (IRB no.: 317-2016). The ethics committee of the KAUH did not require informed consent because of the retrospective design of the study. Patient confidentiality was guaranteed because in the database that was developed for this study no patient identifiers such as name, initials, date of birth or unique hospital identification number were documented. At the moment of the procedure, treatment selection was according to the internal and hospital guidelines and also the principles of the Declaration of Helsinki were adhered.

\section{DESyne coronary stent system}

The DESyne coronary stent system has been described previously. ${ }^{12}$ In summary, the stent is made of a cobalt-chromium alloy and is available in diameters of 2.5, 3.0 and $3.5 \mathrm{~mm}$ and in 14, 18, 23 and $28 \mathrm{~mm}$ lengths. The stent has a nominal strut thickness of $0.0032^{2}(0.08 \mathrm{~mm})$ with an eight-crown pattern for the 3.0 and $3.5 \mathrm{~mm}$ sizes and a six-crown pattern for the $2.5 \mathrm{~mm}$ sizes. The DESyne stent is loaded with $5 \mu \mathrm{g}$ of novolimus per millimeter of stent length. The stent is coated with a formulation composed of novolimus and a durable methacrylate polymer which allows sustained release of $80 \%$ of the drug over a period of $\sim 12$ weeks and $100 \%$ by 6 months.

\section{Clinical procedure}

The procedures were performed by expert interventional cardiologists at the KAUH according to the standard hospital interventional techniques. Selection of the DESyne stent for each individual patient was at operator's discretion. Patients who have not previously taken acetylsalicylic acid received a loading dose of $\geq 300 \mathrm{mg}$ before the procedure. In addition, patients received, at the time of the procedure, 300-600 mg of clopidogrel if they have not received it during the 7 days preceding the procedure. Anticoagulation during the procedure was achieved with unfractionated heparin at a dose of $5,000 \mathrm{IU}$ or $70-100 \mathrm{IU} / \mathrm{kg}$ of body weight to maintain an activated clotting time of more than 250 seconds. All patients were discharged with a prescription for at least $75 \mathrm{mg}$ of indefinitely acetylsalicylic acid and for $75 \mathrm{mg}$ of clopidogrel for a minimum of 6 months after the indexed procedure. Prasugrel or ticagrelor instead of clopidogrel was administered for high-risk acute coronary syndrome patients.

\section{Clinical events, follow-up end points and definitions}

Event collection was composed of all major adverse cardiac events (MACEs) and stent thrombosis. MACE was defined as cardiac death, myocardial infarction (MI) not clearly attributable to a noninterventional vessel and clinically 
indicated target lesion revascularization. For death and its subcategories, the definitions as formulated by the Academic Research Consortium (ARC) were applied. ${ }^{13}$ Cardiac death was defined as any death due to immediate cardiac cause (eg, MI, low output failure and fatal arrhythmia). Unwitnessed death and death of unknown cause were classified as cardiac deaths. In addition, this included all procedure-related deaths including those related to concomitant treatment. A vascular death was defined as death due to cerebrovascular disease, pulmonary embolism, ruptured aortic aneurysm, dissecting aneurysm or other vascular causes. Noncardiovascular death was any death not covered by the abovementioned definitions, including death due to infection, sepsis, pulmonary causes, accident, suicide or trauma.

The third universal definition of MI was used for the classification of suspected MIs. ${ }^{14}$ A periprocedural MI within the first 48 hours after the procedure was defined as an elevation of troponin values $(>5 \times 99$ th percentile upper reference limit [URL]) in patients with normal baseline values $(\leq 99$ th percentile URL). A spontaneous Q-wave MI ( $>48$ hours after intervention) required the development of new pathological Q-waves in two or more contiguous leads (as assessed by the electrocardiography [ECG] core laboratory) with or without post-procedural troponin, creatine kinase or creatine kinase-MB levels elevated above normal. A spontaneous non-Q-wave MI required the detection of a rise and/or fall of cardiac biomarker values with at least one value above the 99th percentile URL and with at least one of the following: symptoms of ischemia, new or presumed new significant STsegment T-wave (ST-T) changes or new left bundle branch block, development of pathological Q-waves, imaging evidence of new loss of viable myocardium or new regional wall motion abnormality or the identification of an intracoronary thrombus by angiography or autopsy. For all definitions, any MI not clearly attributable to a nontarget vessel was considered as target vessel MI. Repeat revascularizations were classified according to the ARC criteria. ${ }^{13}$ Target lesion revascularization was defined as any repeat percutaneous intervention of the target lesion or bypass surgery of the target vessel performed for restenosis or other complications of the target lesion. The target lesion was defined as the treated segment from $5 \mathrm{~mm}$ proximal to the stent and to $5 \mathrm{~mm}$ distal to the stent. Target vessel revascularization was defined as any repeat percutaneous intervention or surgical bypass of any segment of the target vessel. The target vessel was defined as the entire major coronary vessel proximal and distal to the target lesion, which includes upstream and downstream branches and the target lesion itself. A revascularization was considered clinically indicated if angiography at follow-up shows a percent diameter stenosis of $>50 \%$ and if one of the following occurs: 1) a positive history of recurrent angina pectoris, presumably related to the target vessel; 2) objective signs of ischemia at rest (ECG changes) or during exercise test (or equivalent), presumably related to the target vessel; 3) abnormal results of any invasive functional diagnostic test (eg, Doppler flow velocity reserve and fractional flow reserve); 4) A target lesion revascularization or target vessel revascularization with a diameter stenosis of $>70 \%$ even in the absence of the abovementioned ischemic signs or symptoms. Stent thrombosis data are reported according to the ARC definitions. ${ }^{13}$ A definite thrombosis was defined in case there was an angiographic or pathologic confirmation of a thrombus. A probable stent thrombosis was considered to have occurred for any unexplained death within the first 30 days after the procedure and, irrespective of the time after the procedure, for any MI in the territory of the implanted stent. A possible stent thrombosis was considered for any unexplained death after 30 days.

\section{Statistical analyses}

The primary analytical population consisted of all patients implanted with a DESyne stent. Data were analyzed with Minitab 17 Statistical Software. Data for all continuous variables were summarized with descriptive statistics (mean, median, SD, minimum and maximum). Data for all categorical variables were summarized with subject counts and percentages. Event rates at 30 days, 6 months and 1 year were calculated according to the Kaplan-Meier method, and Kaplan-Meier plots were generated for the main cardiac events.

\section{Results}

\section{Patient demographics}

A total of 715 patients were treated with the DESyne stent between July 22, 2013, and September 10, 2016. The baseline demographics showed a mean age of $57.8 \pm 10.3$ years. The male enrollment was $79.3 \%$, and $11.2 \%$ had a history of smoking, while $53.0 \%$ were listed as still smoking at the time of the procedure. A total $58.3 \%$ of patients had a history of diabetes mellitus. The prevalence of hyperlipidemia was $88.1 \%$. In addition, $23.1 \%$ had a positive family history in a first-degree relative for premature coronary artery disease. The medical history showed that $38.2 \%$ and $2.7 \%$ of the patients had experienced a previous Q-wave or non-Q-wave MI, respectively. The majority (64.3\%) of the infarctions occurred within 12 hours of the procedure. The 
patient history also revealed a previous PCI in $45.7 \%$ and a previous coronary artery bypass graft surgery (CABG) in $3.9 \%$. The current cardiac status at baseline was unstable angina in $72.0 \%$ and (acute) MI in $14.3 \%$ of the subjects. The patients' demographics and medical history are summarized in Table 1.

\section{Vessel, lesion and procedure characteristics}

The 715 enrolled subjects had 849 lesions in which a DESyne stent was implanted (mean 1.2 lesions per patients: ranged from 1 to 4 lesions per patient). The brachial or radial access route was selected only for $0.3 \%$ of the patients. The majority of the subjects $(82.3 \%)$ had one lesion being treated; a second lesion that required treatment was presented in $16.4 \%$ of the patients. The most frequently treated vessel was the left anterior descending artery in $49.1 \%$ of the lesions. Multivessel disease was present in $11.2 \%$. The stent was implanted in $44.1 \%$ of the lesions at the mid-segment of the vessel; $8.6 \%$ of the lesions were ostial. The vast majority of the lesions (74.6\%) were type A of the American College of Cardiology/American Heart Association lesion classification; type $\mathrm{B} 2$ or $\mathrm{C}$ was reported for $6.1 \%$ and $2.3 \%$ of the lesions, respectively. The mean lesion length was $24.9 \pm 12.6 \mathrm{~mm}$; the mean reference vessel diameter was $3.0 \pm 0.4 \mathrm{~mm}$. In total, 941 DESyne stents were implanted in a total of 849 lesions (1.1 stent per lesion). The mean diameter was $2.94 \pm 0.36 \mathrm{~mm}$, and the mean length was $23.2 \pm 7.6 \mathrm{~mm}$.

In two subjects, no DESyne stent was implanted in any of the lesions because of the failure to reach the target lesion. A second DESyne was implanted in $9.9 \%$ of the lesions. In addition, a total of 104 drug-eluting stents and seven bare metal stents were implanted. Patients were discharged after a mean of $1.8 \pm 8.0$ days (range $0-167$ days) with aspirin in 99.6\% and a P2Y12 inhibitor (clopidogrel, prasugrel or ticagrelor) in $96.7 \%$ of the patients, and the complete details are listed in Tables 2 and 3.

\section{Clinical events}

The 30-day event rate for all deaths was $0.2 \%$. At 6 months and 1 year, the percentages were $0.2 \%$ and $1.1 \%$, respectively. For cardiac death, the event rate at these time points was $0.2 \%, 0.4 \%$ and $0.6 \%$, respectively. At 30 days, the event rate for all MIs was $0.6 \%$. The event rate for all MIs, Q-wave MI and non-Q-wave MIs was $0.9 \%, 0.6 \%$ and $0.3 \%$, respectively, at 1 year. The ischemia-driven target lesion revascularization rate was $0.8 \%$ at 1 year. None of the patients underwent coronary artery bypass surgery. For
Table I Patient characteristics $(\mathrm{N}=7 \mid 5)$

\begin{tabular}{|c|c|}
\hline Patient characteristics; 715 patients & DESyne (n/N) \\
\hline Age (years); mean \pm SD & $57.8 \pm 10.3$ \\
\hline $\mathrm{N}$ & 713 \\
\hline Age range (years) & $26-86$ \\
\hline Male & $79.3 \%(567 / 7 / 5)$ \\
\hline Female & $20.7 \%(|48 / 7| 5)$ \\
\hline History of smoking & $1 \mathrm{I} .2 \%(80 / 7 \mid 5)$ \\
\hline Current smoker & $53.0 \%(379 / 7 / 5)$ \\
\hline Hyperlipidemia & $88.1 \%(629 / 7 / 4)$ \\
\hline Diabetes mellitus & $58.3 \%(4 \mid 7 / 7 / 5)$ \\
\hline Hypertension & $68.3 \%(488 / 7 \mid 4)$ \\
\hline Prior MI & $40.1 \%(287 / 7 / 4)$ \\
\hline Q-waves & $38.2 \%(273 / 7 \mid 4)$ \\
\hline Non-Q-waves & $2.7 \%(19 / 7 / 5)$ \\
\hline Premature CAD in a first-degree relative & $23.1 \%(165 / 7 / 3)$ \\
\hline Prior percutaneous coronary revascularization & $45.6 \%(326 / 7 / 4)$ \\
\hline Prior CABG & $3.9 \%(28 / 7 / 5)$ \\
\hline \multicolumn{2}{|l|}{ Current cardiac status } \\
\hline Stable angina & $13.7 \%(98 / 7 \mid 4)$ \\
\hline Unstable angina & $72.0 \%(5|4 / 7| 4)$ \\
\hline STEMI & $10.2 \%(73 / 7 \mid 4)$ \\
\hline NSTEMI (\%) & $4.1 \%(29 / 7 \mid 4)$ \\
\hline \multicolumn{2}{|l|}{ STEMI } \\
\hline$<6$ hours & $32.9 \%(23 / 70)$ \\
\hline $6-12$ hours & $31.4 \%(22 / 70)$ \\
\hline I2-24 hours & $14.3 \%(10 / 70)$ \\
\hline $24-48$ hours & $8.6 \%(6 / 70)$ \\
\hline$>48$ hours & $12.9 \%(9 / 70)$ \\
\hline \multicolumn{2}{|l|}{ NSTEMI } \\
\hline$<6$ hours & $14.3 \%(4 / 28)$ \\
\hline $6-12$ hours & $17.9 \%(5 / 28)$ \\
\hline $12-24$ hours & $25.0 \%(7 / 28)$ \\
\hline $24-48$ hours & $14.3 \%(4 / 28)$ \\
\hline$>48$ hours & $28.6 \%(8 / 28)$ \\
\hline Patients dialyzed & $1.3 \%(9 / 7 / 5)$ \\
\hline Renal transplant & $0.6 \%(4 / 7 / 0)$ \\
\hline
\end{tabular}

Abbreviations: $C A B G$, coronary artery bypass graft surgery; CAD, coronary artery disease; MI, myocardial infarction; NSTEMI, non-ST elevation MI; STEMI, ST elevation MI.

definite/probable, definite and probable stent thrombosis, the estimated rates were $0.7 \%, 0.3 \%$ and $0.7 \%$, respectively. At 1 year, these were $1.1 \%, 0.5 \%$ and $0.6 \%$, respectively (Figure 1 and Table 4).

\section{Discussion}

The aim of this study was to evaluate the safety and performance of the DESyne coronary metallic stent used in daily practice in a single university center in Jordan. The stent delivery success rate (>99\%) was high, and the cardiac event rate at 1 year was low with low rates for cardiac death $(0.6 \%)$, all MIs $(0.9 \%)$ and an acceptable stent thrombosis rate $(1.1 \%){ }^{15,16}$ The patient population enrolled was a typical - yet unique - daily life population for this referral center with a remarkably high percentage of diabetes mellitus and 
Table 2 Procedure and device characteristics

\begin{tabular}{|c|c|}
\hline Procedure and device characteristics & $\begin{array}{l}\text { DESyne } \\
\text { ( } N=715 \text { patients) } \\
\text { ( } N=849 \text { lesions) }\end{array}$ \\
\hline \multicolumn{2}{|l|}{ Access route } \\
\hline Femoral & $99.7 \%(7|I / 7| 3)$ \\
\hline Brachial/radial & $0.3 \%(2 / 7 / 3)$ \\
\hline \multicolumn{2}{|l|}{ Number of lesions treated per patient } \\
\hline $\mathrm{I}$ & $82.3 \%(587 / 849)$ \\
\hline 2 & $16.4 \%(117 / 849)$ \\
\hline 3 & $1.1 \%(8 / 849)$ \\
\hline 4 & $0.1 \%(1 / 849)$ \\
\hline Multiple vessels & II.2\% (80/7I5) \\
\hline \multicolumn{2}{|l|}{ Number of DESyne stents implanted per lesion } \\
\hline 0 & $2.1 \%(18 / 845)$ \\
\hline 1 & $86.3 \%(729 / 845)$ \\
\hline 2 & $9.9 \%(84 / 845)$ \\
\hline 3 & $1.4 \%(12 / 845)$ \\
\hline 4 & $0.2 \%(2 / 845)$ \\
\hline Diameter of DESyne stent $(\mathrm{mm})$ & $2.94 \pm 0.36$ \\
\hline $\mathrm{N}$ & 936 \\
\hline Range (mm) & $2.5-4.0$ \\
\hline Length of DESyne stent $(\mathrm{mm})$ & $23.2 \pm 7.6$ \\
\hline $\mathrm{N}$ & 938 \\
\hline Range (mm) & $14-38$ \\
\hline \multicolumn{2}{|l|}{$\begin{array}{l}\text { Number of other drug-eluting stents implanted } \\
\text { per lesion }\end{array}$} \\
\hline 0 & $89.1 \%(75 I / 842)$ \\
\hline $\mathrm{I}$ & $9.5 \%(80 / 842)$ \\
\hline 2 & $1.2 \%(10 / 842)$ \\
\hline 3 & $0.0 \%(0 / 842)$ \\
\hline 4 & $0.1 \%(1 / 842)$ \\
\hline \multicolumn{2}{|l|}{$\begin{array}{l}\text { Number of bare metal stents implanted per } \\
\text { lesion }\end{array}$} \\
\hline 0 & $99.2 \%(818 / 825)$ \\
\hline 1 & $0.8 \%(7 / 825)$ \\
\hline \multicolumn{2}{|l|}{ Post-procedural hospital length of stay (days) } \\
\hline $\mathrm{n}^{\mathrm{a}}$ & 667 \\
\hline Mean \pm SD & $1.8 \pm 8.0$ \\
\hline Minimum, maximum & $0-172$ \\
\hline
\end{tabular}

Notes: ${ }^{\mathrm{N} N u m b e r}$ of patients/lesions with evaluable data.

other cardiovascular risk factors, and a significant number of patients presented with an acute coronary syndrome (unstable angina or an acute or recent MI). ${ }^{17}$

Prevalence of cardiovascular risk factors in patients scheduled for PCI is high in Jordan. The first Jordanian PCI study reported a high prevalence of hypertension, diabetes mellitus and hypercholesterolemia with the presence of multiple risk factors in a significant percentage of the patients. ${ }^{17}$ The prevalence of risk factors in this single-center DESyne study is comparable to the prevalence of risk factors of the reported Jordan multicenter study noting that KAUH was one of the participating centers. Nevertheless, the prevalence is in
Table 3 Lesion characteristics

\begin{tabular}{|c|c|}
\hline Lesion characteristics & $\begin{array}{l}\text { DESyne } \\
\text { ( }=715 \text { patients) } \\
\text { ( }=849 \text { lesions) }\end{array}$ \\
\hline \multicolumn{2}{|l|}{ Vessel location (per lesion) } \\
\hline LAD & $49.1 \%(416 / 847)$ \\
\hline LCX & $23.8 \%(202 / 847)$ \\
\hline RCA & $25.9 \%(219 / 847)$ \\
\hline Left main & $0.4 \%(3 / 847)$ \\
\hline Saphenous vein/arterial graft & $0.8 \%(7 / 847)$ \\
\hline \multicolumn{2}{|l|}{ Lesion location (per lesion) } \\
\hline Proximal & $38.1 \%(323 / 847)$ \\
\hline Mid & $44.2 \%(374 / 847)$ \\
\hline Distal & $9.1 \%(77 / 847)$ \\
\hline Ostial & $8.6 \%(73 / 847)$ \\
\hline \multicolumn{2}{|l|}{ Lesion type } \\
\hline De novo & $92.9 \%(784 / 844)$ \\
\hline Restenosis after previous balloon angioplasty & $0.6 \%(5 / 844)$ \\
\hline In-stent restenosis & $5.6 \%(47 / 844)$ \\
\hline Others & $0.9 \%(8 / 844)$ \\
\hline \multicolumn{2}{|l|}{ Lesion class ACC/AHA } \\
\hline $\mathrm{A}$ & $74.6 \%(622 / 834)$ \\
\hline $\mathrm{BI}$ & $17.0 \%(142 / 834)$ \\
\hline B2 & $6.1 \%(51 / 834)$ \\
\hline $\mathrm{C}$ & $2.3 \%(19 / 834)$ \\
\hline \multicolumn{2}{|l|}{ Calcification } \\
\hline None/mild & $87.7 \%(737 / 840)$ \\
\hline Moderate & $11.2 \%(94 / 840)$ \\
\hline Severe & $\mathrm{I} .1 \%(9 / 840)$ \\
\hline \multicolumn{2}{|l|}{ Tortuosity } \\
\hline$<45^{\circ}$ & $94.3 \%(793 / 84 I)$ \\
\hline $45-90^{\circ}$ & $5.3 \%(48 / 84 I)$ \\
\hline \multicolumn{2}{|l|}{ Pre-procedural TIMI } \\
\hline 0 & $8.6 \%(73 / 847)$ \\
\hline $\mathrm{I}$ & $0.8 \%(7 / 847)$ \\
\hline 2 & $10.5 \%(89 / 847)$ \\
\hline 3 & $80.0 \%(678 / 847)$ \\
\hline \multicolumn{2}{|l|}{ Pre-procedural angiogram } \\
\hline \multicolumn{2}{|l|}{ RVD (mm) } \\
\hline $\mathrm{n}^{\mathrm{a}}$ & 846 \\
\hline Mean \pm SD & $3.0 \pm 0.4$ \\
\hline Minimum, maximum & $2.0,4.0$ \\
\hline \multicolumn{2}{|l|}{ MLD (mm) } \\
\hline $\mathrm{n}^{\mathrm{a}}$ & 842 \\
\hline Mean \pm SD & $0.4 \pm 0.3$ \\
\hline Minimum, maximum & $0.0,1.9$ \\
\hline \multicolumn{2}{|l|}{ Diameter of stenosis (\%) } \\
\hline $\mathrm{n}^{\mathrm{a}}$ & 840 \\
\hline Mean \pm SD & $85.6 \pm 10.5$ \\
\hline Minimum, maximum & 50,100 \\
\hline \multicolumn{2}{|l|}{ Lesion length $(\mathrm{mm})$} \\
\hline $\mathrm{n}^{\mathrm{a}}$ & 843 \\
\hline Mean \pm SD & $24.9 \pm 12.6$ \\
\hline Minimum, maximum & 6,108 \\
\hline
\end{tabular}

Note: aNumber of lesions with evaluable data.

Abbreviations: RCA, right coronary artery; TIMI, thrombolysis in myocardial infarction; RVD, reference vessel diameter; MLD, minimal luminal diameter; ACC/ AHA, American College of Cardiology/American Heart Association; LAD, left anterior descending artery; LCX, left circumflex artery. 

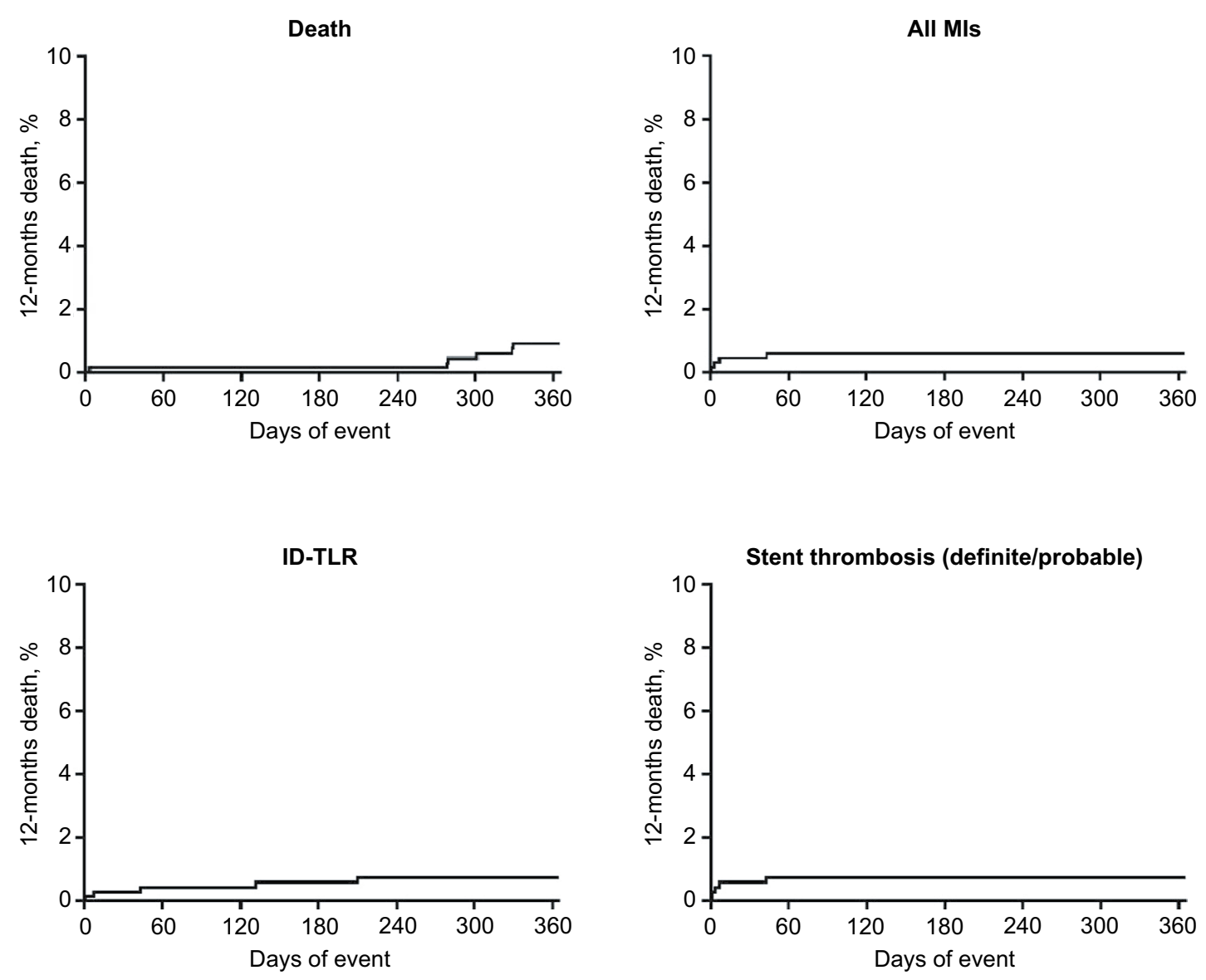

Figure I Kaplan-Meier plots (survival curves) for the main cardiac end points reported at 30 days, 6 months and I year. Abbreviations: ID-TLR, ischemia-driven-target lesion revascularization; MI, myocardial infarction.

Table 4 Event-free survival for cardiac events at 30 days, 6 months and I year according to Kaplan-Meier estimates

\begin{tabular}{|l|l|l|l|}
\hline Percentage & $\mathbf{3 0}$ days & $\mathbf{6}$ months & I year \\
\hline All deaths & 0.2 & 0.2 & $\mathrm{I} . \mathrm{I}$ \\
\hline Cardiac death & 0.2 & 0.4 & 0.6 \\
\hline Noncardiac death & 0.0 & 0.0 & 0.5 \\
\hline All Mls & 0.6 & 0.7 & 0.9 \\
\hline Q-wave MI & 0.3 & 0.4 & 0.6 \\
\hline Non-Q-wave MI & 0.3 & $0.3 I . I$ & 0.3 \\
\hline ID-TLR & 0.3 & 0.6 & 0.8 \\
\hline ID-TVR non-TLR & 0.0 & 0.0 & 0.5 \\
\hline Non-ID-TLR & 0.0 & 0.2 & 0.3 \\
\hline CABG & 0.0 & 0.0 & 0.0 \\
\hline $\begin{array}{l}\text { Definite/probable } \\
\text { stent thrombosis }\end{array}$ & 0.7 & 0.9 & 1.1 \\
\hline $\begin{array}{l}\text { Definite stent } \\
\text { thrombosis }\end{array}$ & 0.3 & 0.5 & 0.5 \\
\hline $\begin{array}{l}\text { Probable stent } \\
\text { thrombosis }\end{array}$ & 0.4 & 0.4 & 0.6 \\
\hline
\end{tabular}

Abbreviations: CABG, coronary artery bypass graft surgery; ID-TLR, ischaemiadriven target vessel revascularization; MI, myocardial infarction.

the same high range: hypertension $68.3 \%$ and $62.3 \%$, diabetes mellitus $58.3 \%$ and $53.6 \%$, hypercholesterolemia $88.1 \%$ and $48.8 \%$ and current smoking $53.0 \%$ and $43.5 \%$ for the DESyne study and the first Jordanian PCI study, respectively.
Outcomes of the first Jordanian PCI study have been reported in a separate article. ${ }^{16}$ In total, 2,426 patients were enrolled whom underwent a PCI at 12 tertiary-care centers in Jordan. The mean age was $56 \pm 11$ years, and $79 \%$ were male. The majority (77\%) underwent their PCI for an acute coronary syndrome. One and two vessels were treated in $71.4 \%$ and $23.7 \%$ of the patients, respectively. At 1 year, the mortality was $1.94 \%$. A percutaneous target vessel revascularization was performed in $3.38 \%$ and a CABG in $0.58 \%$ of the patients. A stent thrombosis occurred in $1.94 \%$. The authors contributed the low event rate, despite the high proportion of acute coronary syndrome patients, to the relatively young age that was several years younger than in registries of the Western population. The clinical outcomes of this multicenter study, and in particular the low percutaneous or surgical re-intervention rates, are comparable to the outcomes of the DESyne study.

At 1 year, $1.1 \%$ of the patients had died which is within the range of $1.0-4.0 \%$ (weighted mean: $2.1 \%$ ) summarized for a large number of individual studies that evaluated contemporary drug-eluting stent in unselected patient populations. ${ }^{18}$ The fact that the incidence of all deaths in the Jordan DESyne study is comparable is in particular important as death - as an end point 
- is independent of the used study definition and constitutes the most relevant clinical outcome. The outcomes for the other end points such as MI, percutaneous re-interventions and CABGs are somewhat lower than usually reported for stent studies performed in western Europe or USA. This can be contributed in part to differences in medical care. For example, the incidence of peri-procedural infarctions is dependent on the frequency of post-procedural biomarker measurement besides the sensitivity of the used definition. ${ }^{14}$ In randomized, controlled studies, post-procedural enzyme measurement is usually study protocol mandated and multiple samples are taken over a period of 1-2 days, while in registries enzyme measurement is often done per hospital routine, ie, less often or only in case the patient develops signs or symptoms of myocardial ischemia. This less frequent biomarker sampling methodology as applied in the Jordan DESyne study - as in most registries - can lead to a lower rate of reported peri-procedural infarctions. In addition, differences in insurance for medical care could have contributed to a difference in the lower incidence of re-interventions, either percutaneously or surgically.

As the limitation of the DESyne study, its retrospective design with its inherent suboptimal precision should be mentioned. The high compliance of the baseline data and the high degree of comparability of the patient characteristics of this study vs the first Jordanian PCI study support the high accuracy patient record maintenance. The KAUH utilizes an electronic patient record system to document patient's health information from which the relevant patient data were retrieved. Moreover, angiograms were reviewed for information not available in the electronic records. In addition, not all patients have been followed for the entire follow-up period of 1 year. Therefore, the incidence of events has been calculated according to the Kaplan-Meier method to account for patients with incomplete follow-up.

In summary, the next-generation DESyne coronary stent system has been evaluated in unselected patients with an indication for a percutaneous intervention at a Jordan tertiary center. The patient population is relatively young with a high prevalence of cardiovascular risk factors presenting predominantly with an acute coronary syndrome as indication. The 1-year event rates of death, MI and re-intervention are low and comparable to other stent studies demonstrating the safety and efficacy of the DESyne stent.

\section{Conclusion}

In this large retrospective study, an all-comer population of patients with an indication for a PCI with the implantation of a DESyne drug-eluting stent was included. The population had a high prevalence of risk factors for coronary artery disease, and a high percentage of patients presented with an acute coronary syndrome including acute MIs. The 1-year incidence of cardiac death $(0.6 \%)$, MI $(0.9 \%)$ and target lesion revascularizations $(0.8 \%)$ was low. The definite/probable stent thrombosis rate was $1.1 \%$.

\section{Disclosure}

The authors report no conflicts of interest in this work.

\section{References}

1. Bennett J, Dubois C. Percutaneous coronary intervention, a historical perspective looking to the future. J Thorac Dis. 2013;5(3):367-370.

2. Williams DO, Holubkov R, Yeh W, et al. Percutaneous coronary intervention in the current era compared with 1985-1986: the National Heart, Lung, and Blood Institute Registries. Circulation. 2000;102(24): 2945-2951.

3. Sigwart U, Puel J, Mirkovitch V, Joffre F, Kappenberger L. Intravascular stents to prevent occlusion and restenosis after transluminal angioplasty. N Engl J Med. 1987;316(12):701-706.

4. Serruys PW, de Jaegere P, Kiemeneij F, et al. A comparison of balloonexpandable-stent implantation with balloon angioplasty in patients with coronary artery disease. Benestent Study Group. $N$ Engl J Med. 1994;331(8):489-495.

5. Menown IB, Noad R, Garcia EJ, Meredith I. The platinum chromium element stent platform: from alloy, to design, to clinical practice. $A d v$ Ther. 2010;27(3):129-141.

6. Nakamura S, Hall P, Gaglione A, et al. High pressure assisted coronary stent implantation accomplished without intravascular ultrasound guidance and subsequent anticoagulation. J Am Coll Cardiol. 1997;29(1):21-27.

7. Sabouret P, Rushton-Smith SK, Kerneis M, Silvain J, Collet JP, Montalescot G. Dual antiplatelet therapy: optimal timing, management, and duration. Eur Heart J Cardiovasc Pharmacother. 2015;1(3):198-204.

8. Moses JW, Leon MB, Popma JJ, et al. Sirolimus-eluting stents versus standard stents in patients with stenosis in a native coronary artery. $N$ Engl J Med. 2003;349(14):1315-1323.

9. Fajadet J, Wijns W, Laarman GJ, et al. Randomized, double-blind, multicenter study of the Endeavor zotarolimus-eluting phosphorylcholineencapsulated stent for treatment of native coronary artery lesions: clinical and angiographic results of the ENDEAVOR II trial. Circulation. 2006;114(8):798-806.

10. Garg S, Serruys PW. An update on drug-eluting stents. Curr Treat Options Cardiovasc Med. 2013;15(1):61-78.

11. Serruys PW, Silber S, Garg S, et al. Comparison of zotarolimus-eluting and everolimus-eluting coronary stents. N Engl J Med. 2010;363(2): 136-146.

12. Iqbal J, Verheye S, Abizaid A, et al. DESyne novolimus-eluting coronary stent is superior to Endeavor zotarolimus-eluting coronary stent at fiveyear follow-up: final results of the multicentre EXCELLA II randomised controlled trial. EuroIntervention. 2016;12(11):e1336-e1342.

13. Cutlip DE, Windecker S, Mehran R, et al. Clinical end points in coronary stent trials: a case for standardized definitions. Circulation. 2007;115(17):2344-2351

14. Thygesen K, Alpert JS, Jaffe AS, et al. Third universal definition of myocardial infarction. Eur Heart J. 2012;33(20):2551-2567.

15. de La Torre Hernández JM, Alfonso F, Gimeno F, et al. Thrombosis of second-generation drug-eluting stents in real practice results from the multicenter Spanish registry ESTROFA-2 (Estudio Español Sobre Trombosis de Stents Farmacoactivos de Segunda Generacion-2. JACC Cardiovasc Interv. 2010;3(9):911-919.

16. Alhaddad IA, Tabbalat R, Khader Y, et al. Outcomes of middle eastern patients undergoing percutaneous coronary intervention: the primary analysis of the first Jordanian PCI registry. Heart Views. 2017;18(1): $3-7$. 
17. Hammoudeh AJ, Alhaddad IA, Khader Y, et al. Cardiovascular risk factors in middle eastern patients undergoing percutaneous coronary intervention: results from the first Jordanian percutaneous coronary intervention study. J Saudi Heart Assoc. 2017;29(3): 195-202.
18. Tamburino C, Capodanno D, Erglis A, et al. One-year outcomes in unselected patients treated with a thin-strut, platinum-chromium, paclitaxel-eluting stent: primary endpoint results from the TAXUS Element European post-approval surveillance study (TE-PROVE. EuroIntervention. 2015;10(11):1261-1266.

\section{Publish your work in this journal}

Medical Devices: Evidence and Research is an international, peerreviewed, open access journal that focuses on the evidence, technology, research, and expert opinion supporting the use and application of medical devices in the diagnosis, monitoring, treatment and management of clinical conditions and physiological processes. The identification of novel devices and optimal use of existing devices which will lead to improved clinical outcomes and more effective patient management and safety is a key feature. The manuscript management system is completely online and includes a quick and fair peer-review system. Visit http://www. dovepress.com/testimonials.php to read real quotes from authors.

Submit your manuscript here: https://www.dovepress.com/medical-devices-evidence-and-research-journal 